\title{
THE MONITORING AND FEEDBACK ANALYSIS OF THE VAULT SLOPE DEFORMATION FOR THE PERMEABLE RIB DOUBLE-ARCH TUNNEL
}

\author{
Ze-cheng Chi ${ }^{1, a}$, Xiu-he Chen ${ }^{2}$, Fei Wang ${ }^{2}$, Fei $\mathrm{Yu}^{1, \mathrm{~b}}$ and Shan-xiong Chen ${ }^{1}$ \\ ${ }^{1}$ Institute of Rock and Soil Mechanics, Chinese Academy of Sciences, Wuhan 430071, China; \\ ${ }^{2}$ Anhui Communications Planning, Design and Research Institute, Hefei 230041, China. \\ a873540602@qq.com, byufei8720@163.com
}

\begin{abstract}
Keywords: double-arch permeable rib tunnel, rib beam, ground settlement, monitoring measurement, feedback analysis.
\end{abstract}

\begin{abstract}
Based on the features of the structure of double-arch permeable rib tunnel and its spatial deformation mechanism, a corresponding construction monitoring and measuring program was demonstrated in this paper. The reasons of the vault slope deformation and cracking which was the main risk during the construction were analyzed according to the monitoring data. Moreover, through using the method of structural load, a detailed and comprehensive feedback analysis of the stability of lining structure, rib beam and mid-connection wall was made under the most unfavorable construction condition, which was dynam-relaxed rack mass of the vault slope. Finally engineering treatment was proposed to ensure the construction safety and long-term stability of this new-style tunnel.
\end{abstract}

\section{Introduction}

Double-arch permeable rib tunnel, which is a new mountainside-tunnel structure, could be better adaptable to the complicated topography in mountain area. Moreover, the damage of surface vegetation could be avoided as much as possible through this kind of tunnel so that the unification and harmonization of engineering and environment will be achieved.

Double-arch permeable rib tunnel is mainly used in mountainside where the ground surface is inclined. In this section, the overburden layer is thin, the surrounding rock is weathered badly and the bias is serious. As a result, the stability of the vault slop and the tunnel surrounding rock will be affected significantly in tunnel excavation. In addition, the structure of double-arch permeable rib tunnel has the problem of spatial asymmetry which leads to the complex change regularity of stress and strain of structural components such as rib beam, mid-connection wall and second lining. In order to ensure the stability of the tunnel structure and the surrounding rock in construction, a specific and targeted construction monitoring and measuring project should be put forward which is one of the crucial elements in construction safety of this new-style tunnel. Moreover, the feedback analysis of the problems which exist in construction and the timely adjustment of the construction parameters are also necessary [1, 2].

The project of Wangdong Changjiang Road Bridge Nanshan Tunnel, located in the Caodong vallege, Xiangyu Town of Dongzhi County is researched as an example in this paper. It from XX section K27+472 to K27+636, whose total length is 164 meters. Among these sections, double-arch permeable rib tunnel structure is used from the section K27+472 to K27+538. The hillside that the tunnel passed through is steep. And the rock layer which was bored through was mainly in the metasandstone. On the other hand, the shallow-burial of the tunnel. The depth of tunnel; big strew angle, ground line, cave root. Big influence on the deformation and stability of tunnel structure during construction.

Before exacavation, using lateral shed-pipe and grouting technology which support the dome to control the deformation of mountain effectly and improve the rock stability of the vault disturbance zone, Then start exacavating of middle pilot heading and mid-connection wall.

In order to ensure the smooth and successful completion of the tunnel construction, a suitable construction monitoring and measuring program was made based on the features of the structure of 
double-arch permeable rib tunnel and its spatial deformation mechanism the tunnel for structural characteristics and force deformation features. Furthermore, a detailed and comprehensive feedback analysis of the vault crack which is the main risk in construction and its effect on the stability of the structure was made to ensure the safety of the structure in construction.

\section{Tunnel Monitoring and Measuring Program}

Overall Construction Monitoring and Measuring Program. With the reference of the topographical and geological conditions, the vault slope formation should be pre-reinforced at first to ensure the stability and security of the formation after which the tunnel construction can be made. Since the double-arch permeable rib tunnel has the serious problem of bias, the process of tunnel excavation is more complex which repeatedly results many disturbance of the formation. In order to ensure the security of tunnel construction, a monitoring program and arrangement of the monitoring-spot arrangement has been made made as below:

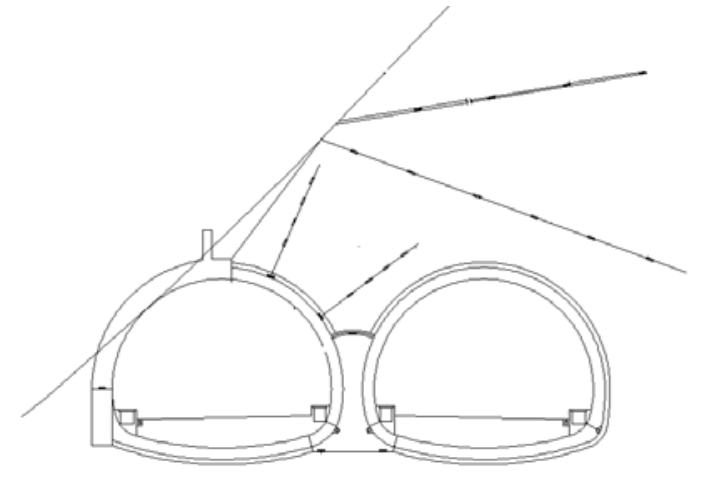

Fig. 1 Monitoring - spot arrangement and structures of double-arch permeable rib tunnel

The Monitoring and Analysis of the Deformation of the Vault Slope. During the tunnel construction, the subsidence of the surface of vault slope increased significantly and quickly. Figure 2 and Figure 3 show the space-time curve of the fast development of the surface subsidence. In these two figures, monitoring-spot 3-1 and 4-1 were located on the surface of the slope above the mid-connection wall and monitoring-spot 3-2 and 4-2 are located on the vault hillside within the section.

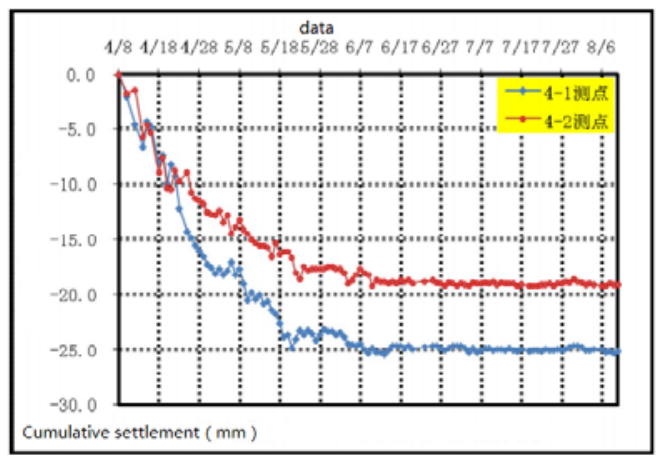

Fig. 2 Space-time curve of surface subsidence in section $\mathrm{K} 27+532$

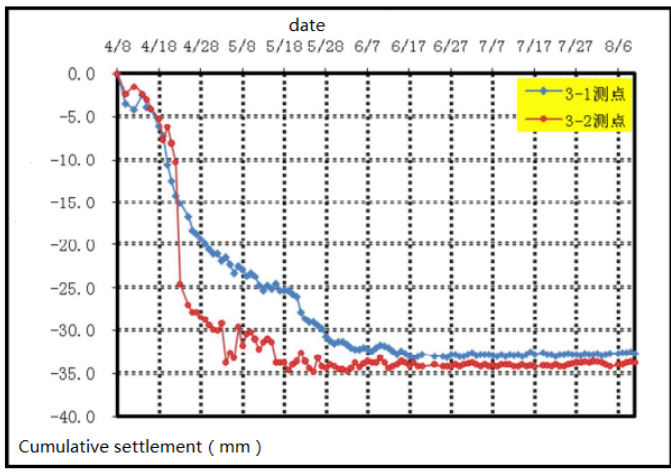

Fig. 3 Space-time curve of surface subsidence in section $\mathrm{K} 27+526$

It can be seen from the figure that from mid-April 2014 to early May, the settlement of the vault hillside grew rapidly which could totally reached to $25 \sim 35 \mathrm{~mm}$. To be more specific, during this period, the maximum subsidence rate appeared in mid-April. The settlement of the Section K27 + 526 which was near to the cave entrance was approximately $10 \mathrm{~mm}$ higher than that of the Section K27 + 532. The reasons of the dramatic changes of the settlement are illustrated below with the reference of the actual stage of excavation and geological conditions. 


\section{The Analysis of the Reasons of the Vault Slope Deformation and Cracking}

Construction of the Dome Surface Cracking Condition. By April 8, 2014, the excavation of the right hole of the rib segment lining had been completed for nearly four months as well as the initial support. However, secondary lining was not done. On April 10th, the excavation of the left tunnel of the rib lining Section K27 + 538 to K27 + 520 was started as well as the construction of the steel arch and the broadening of the lateral base.From the time curve of the vault hillside settlement, it is clear that the surface subsidence began to increase quickly after the left tunnel excavation. On April 18 of 2014, longitudinal crack which was 1 to $2 \mathrm{~cm}$ wide and 7 to 8 long had been found on the section K27 + $538 \sim$ K27 +520 of the vault hillside (See Figure 4). Moreover, there was a trend of further expansion of crack which was on the hillside surface of the right side of the cave, shown in Figure 5.

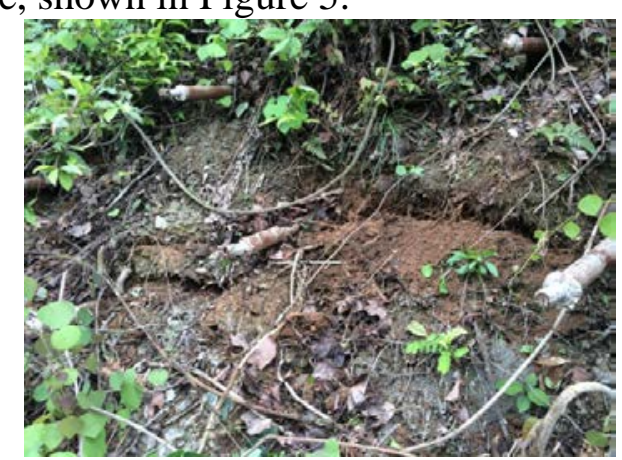

Fig. 4 A photo of surface cracks in the hillside

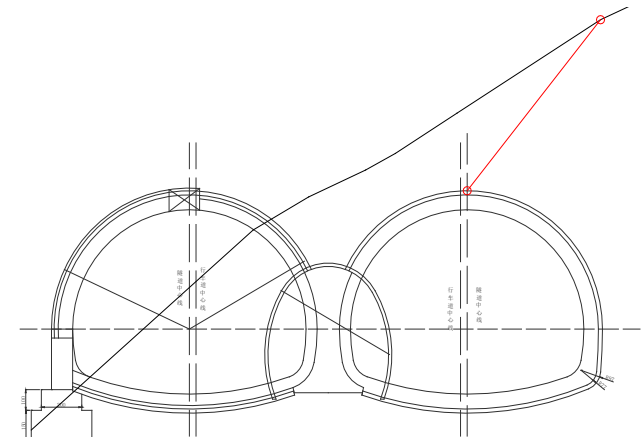

Fig. 5 The position of surface crack and the main loose region

The Analysis of the Cause of Surface Crack. considering the progress and the real conditions of the construction, the causes of the engineering problems mentioned above are listed in details as below:

(1) The cover layer of this section was relatively thinner. Due to the surrounding rock crushing and joints fractured, the self-stability is poor. Moreover, the geological conditions in the actual construction were complex with lots of changes.

(2) It had been put for a long time after the advanced excavation of the right rib segment lining hole. Moreover, due to the sufficient spring rainfall, the rainwater infiltration affected the stability of rock slopes significantly in the construction process which adversely resulted in the continuous de formation of the vault hillside surrounding rock.

(3) The tunnel area located bias, bias effect significant construction excavation hole left rib lining segments, the right hole excavated section of the secondary lining is not applied for, vault lack of effective support hillside surrounding rock deformation displacement is too large;

(4) The dome hillside pipe roof grouting surrounding rock fracture is not completely filled, there is still localized through the cracks, there is a certain impact on the overall stability of the hillsides vault.

\section{Inverse Analysis of Stability of the Surrounding Rock and Structure}

Due to the engineering problems discussed above, a feedback analysis of the stability of the vault slope, the range of surrounding rock relaxation and the force of the tunnel structure is needed in order to evaluate the risks which may happen.

The Analysis of the Stability of the Vault Slop. Wangjiang portal section of the tunnel was located in the slope area, where the natural slope of the ramp was about $40^{\circ}$ and the slope is about $355^{\circ}$. The cover layer of the quaternary was thin . Quaternary cover, is strongly weathered bedrock outcropping metamorphic sandstone; ribbed arch segment $(\mathrm{K} 27+472 \sim \mathrm{K} 27+538)$ for the $\mathrm{V}$ grade Rock, lithology is mainly a small amount of strongly weathered and weathered metamorphic sandstone, natural state, the tunnel site hillside is stable. 
The excavation of the tunnel broke the original balance of the earth stress field inevitably which led to the redistribution in stress field. Without the reinforcement on the slopes, down the hillside outside roof surrounding a large deformation in the right hole dome showed a greater tensile stress zone, due to the lower strength strong weathered rock, prone to pulling shear failure, in the presence of rock downslope to the joint condition may occur through the dome hillside to slip wedge surface (Fig. 6 shows).

Based on the vault hillside tensile stress zone which was influenced by the excavation of the tunnel, five rows of $89 \mathrm{~mm}$ lateral grouting pipe roof was used in the reinforcement. Through grouting surrounding rock fracture filling, the strength of rock hillside was increased. Meanwhile the overall stability of the hillside was improved by controlling the hillside rock deformation through the use of the anchor pipe roof.

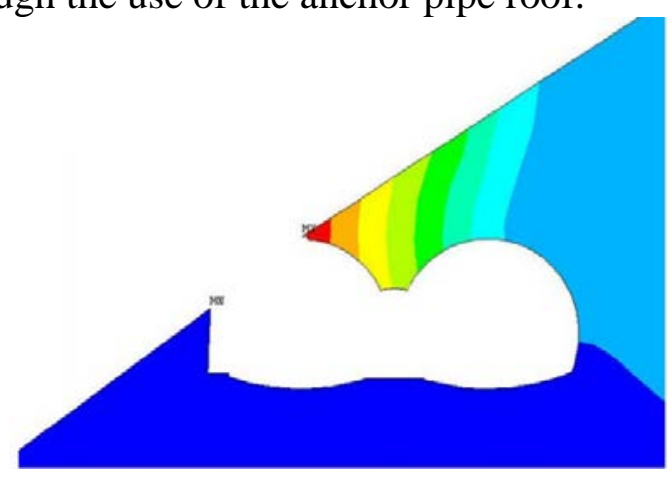

Fig. 6 Surrounding rock displacement nephogram in unreinforced condition

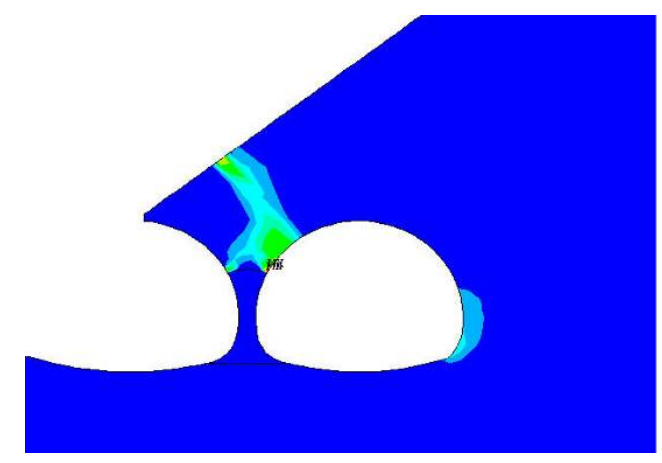

Fig. 7 Surrounding rock plastic zone nephogram in reinforced condition

It can be seen that after the reinforcement of the vault hillside, surrounding rock did not appear significant tensile stress concentration area. Moreover, the plastic zones were mainly in the top of the mid-connection wall and the right holes of the foot arch which showed that the overall vault slope was stable.

In the actual construction, the roof rock of the mid-connection wall was reinforced by they way of hollow bolt grouting, which can effectively improve the stability of the roof rock of the midconnection wall and avoid the risk of partial slump and falling rocks caused by the surrounding rock compression and shear failure. Thus, after the reinforcement of the hillside as the design, vault hillside was stable in the tunnel excavation process. Moreover, the stability of the hillside was improved significantly through the tunnel structure which provided anneffective support for the vault slope.

In the actual construction process, due to the advanced excavation of the right tunnel cave, the worst construction condition was made which was the sharp increase in the hillside rock deformation of the vault slope.

For this actual working conditions, the inverse model was made. The analysis shows that under the right tunnel lining is not formed two conditions, the left tunnel excavation, the distribution range of plastic zones shown in Figure 8, the performance of right tunnel vault extending along a ramp to the slopes of the wedge surface, surface dew point and field position is consistent surface cracks.

Combined with the construction process feedback analysis and field surface cracking circumstances, it can be basically determined the scope of the current vault loose rock slopes mainly extends to the right hole dome roof surrounding surface cracks which is shown in Figure 5, the red line. 


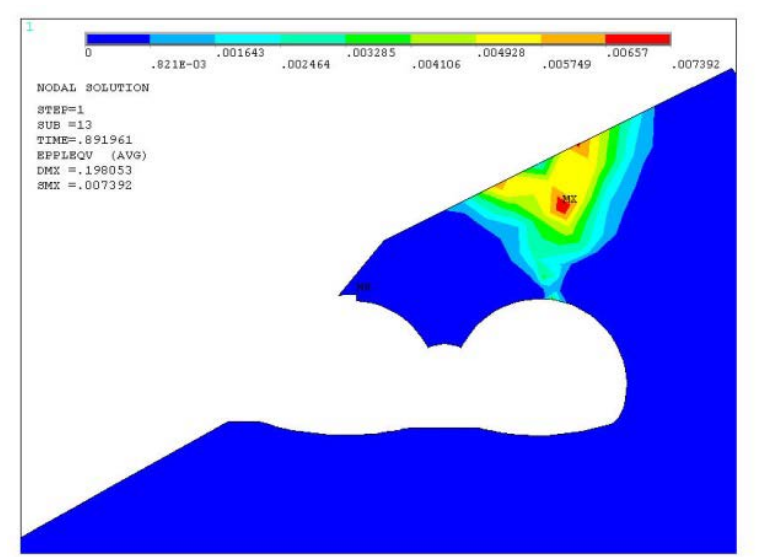

Fig. 8 The distribution map of the plastic

zone in the surrounding rock of the dome

The Structural Internal Force of Tunnel Lining and Strength Stability Analysis. For the above engineering problems, the model of the structural load calculation is established according to the limit state. It's safe for the tunnel structure to analyse the internal force and strength stability .

According to the above analysis, the model and the calculation method of structural load are shown in Figure 9.

Under the most unfavorable damage mode, that is, when the tunnel structure and the ground line intersect at the vault, the internal force of the tunnel lining structure (except the rib beam) is the largest. Among them, the maximum negative moment section at the vault, the maximum positive moment and the maximum shear cross section at the outside of the arch, the maximum axial force section at the inside of the arch, these are shown in Figure 10 and table 1.

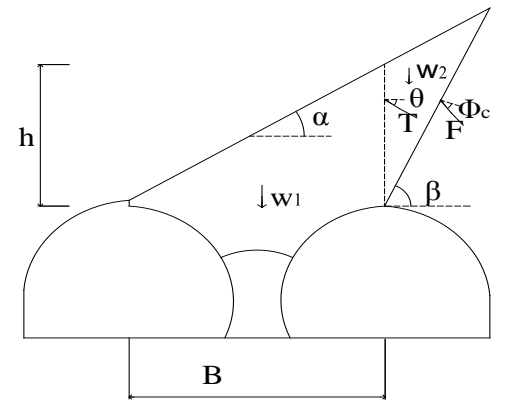

Fig. 9 The model of structural load calculation

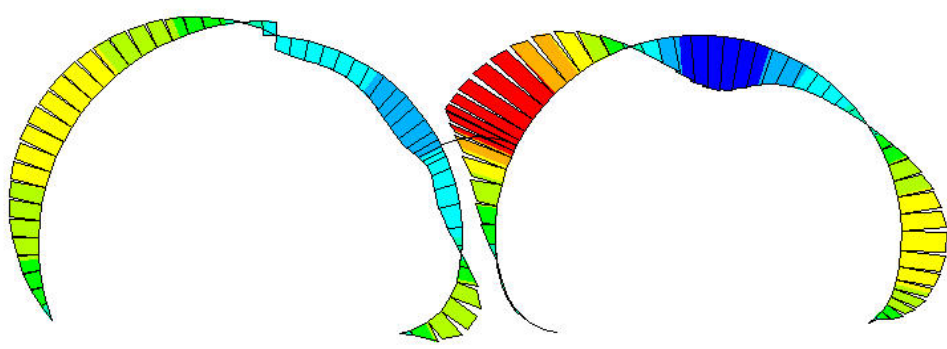

Fig. 10 Bending moment under the most unfavorable conditions

Table 1 Internal force of lining structure under the most unfavorable damage mode

\begin{tabular}{|c|c|c|c|c|}
\hline Structure & Section position & Moment $(\mathrm{kN} \cdot \mathrm{m})$ & Shear $(\mathrm{kN})$ & Axial force $(\mathrm{kN})$ \\
\hline \multirow{3}{*}{ Lining } & Vault & -298.7 & -225.7 & -618.7 \\
\cline { 2 - 5 } & Outside of the arch & 730.2 & 381.3 & -1323.7 \\
\cline { 2 - 5 } & Iutside of the arch & 384.9 & -91.0 & -446.0 \\
\hline
\end{tabular}

According to 《Code for highway tunnel design》(JTG D70-2004), under eccentric compression, checking calculation of lining structural section strength [3]. When the thickness of lining section is $0.6 \mathrm{~m}$, and two-way symmetrical layout HRB335 steel bar (its tensile strength is 335MPa), section bending compressive strength to meet the requirements(in fact, there are eight HRB335 steel bars which the diameter is 22mm are laid ). In the section design, HPB235 steel bar which the diameter is $8 \mathrm{~mm}$ is used as the stirrup. After the calculation of the force of the cross section, per meter of shear strength is $1233.1 \mathrm{kN}$, the maximum shear stress is $381.3 \mathrm{kN}$. Practical design to meet the requirements of cross section shear [4].

In a word, under the current conditions, the strength and stability of the tunnel lining structure is satisfied. 
The Structural Internal Force of Rib Beam and Strength Stability Analysis. In the calculation model, applied load is longitudinal width for surrounding rock of $1 \mathrm{~m}$ sinking of the tunnel structure pressure. Considering the spatial effect of the force of the rib beam, each piece of rib beam withstand surrounding rock pressure in the range of 6 meters wide. Therefore, when checking calculation of the structural stability of the rib beam, the structural load of the model should be expanded 6 times to analyze the internal force of the rib beam.

Under the most unfavorable damage mode, that is, when the rib beam is covered by the surface of the earth, the internal force of the rib beam is the largest. Among them, the maximum shear cross section at the top of the rib beam, the maximum positive moment and the maximum axial force section at the middle of the rib beam, these are shown in table 2.

Table 2 Internal force of rib beam under

the most unfavorable damage mode

\begin{tabular}{|c|c|c|c|c|}
\hline Structure & Section position & Moment $(\mathrm{kN} \cdot \mathrm{m})$ & Shear $(\mathrm{kN})$ & Axial force $(\mathrm{kN})$ \\
\hline \multirow{3}{*}{ Rib beam } & Top of the rib beam & -905.2 & -664.1 & -215.8 \\
\cline { 2 - 5 } & Middle of the rib beam & 1868.4 & -335.6 & -610.8 \\
\cline { 2 - 5 } & Lateral wall & 1313.7 & 321.8 & -431.7 \\
\hline
\end{tabular}

According to 《Code for highway tunnel design》 ( JTG D70-2004), under eccentric compression, checking calculation of rib beam section strength. When the section of the rib beam is made of thick $1.05 \mathrm{~m}$ and wide $1.2 \mathrm{~m}$, and two-way symmetrical layout HRB335 steel bar ( its tensile strength is $335 \mathrm{MPa}$ ), section bending compressive strength to meet the requirements(in fact, there are sixteen steel bars which the diameter is $25 \mathrm{~mm}$ are laid ). In the section design, HPB235 steel bar which the diameter is $8 \mathrm{~mm}$ is used as the stirrup. After the calculation of the force of the cross section, its shear strength is $3040.5 \mathrm{kN}$, the maximum shear stress is $610.8 \mathrm{kN}$ [5]. Practical design to meet the requirements of cross section shear. In a word, under the current conditions, the strength and stability of the rib beam is satisfied.

The Strength of Mid-partition and Anti-overturning Stability Analysis. The mid-partition resistance to bending is the main component of the tunnel. Analyzing the stress and stability of the mid-partition, the tensile stress area of the mid-partition is mainly located at the bottom of it. Among them, the value of maximum tensile stress is $1.3 \mathrm{MPa}$, and the value of maximum compressive stress which is located at the outside of the mid-partition is $4.45 \mathrm{MPa}$. Its strength stability meets the requirements [6].

Deformation of the upper part of mid-partition is mainly horizontal displacement moved outside the hill. In order to meet the requirements of the design, used locking pins installed in the bottom of mid-partition to limit its horizontal displacement.

In addition, analysed the anti-overturning stability of the mid-partition under the current construction condition. As shown in Table 3, the anti-overturning stability safety factor of the midpartition is 2.15, which indicated that the wall is safe enough, even under the most unfavorable conditions.

Table 3 The tableunder of mid-partition anti-overturning analysis under the most unfavorable damage mode

\begin{tabular}{|c|c|c|c|}
\hline Structure & $\begin{array}{c}\text { Overturning } \\
\text { moment }(\mathrm{kN} \cdot \mathrm{m})\end{array}$ & $\begin{array}{c}\text { Anti- overturning } \\
\text { moment }(\mathrm{kN} \cdot \mathrm{m})\end{array}$ & $\begin{array}{c}\text { the anti-overturning stability } \\
\text { safety factor }\end{array}$ \\
\hline mid-partition & 1631.93 & 3511.95 & 2.15 \\
\hline
\end{tabular}

Reinforcement Measures and Effection. According to engineering ways of solving problems and the analysis of structural stability of surrounding rock, the structure of tunnel is stable. The main problems include the deformation of the rock located at the top of the tunnel is too large and some areas of surrounding rock become loose. These will have influence on next construction and 
operation safety. In order to avoid the deformation of the surrounding rock of the tunnel, which influenced the stability and safety of the tunnel's structure, the following measures are taken:

(1) Grouting in the surrounding rock loose region which in the top of the vault to close surface cracks. Treated the drainage of hillside to reduce adverse effects caused by rainwater infiltration, so stability of the mountain can be ensured.

(2) Constructed secondary lining of the right tunnel and the rib beam of the left tunnel as soon as possible, so forming a complete structure of bearing load to limit the deformation of the surrounding rock.

(3) Used ductule(Length is $4.5 \mathrm{~m}$ and diameter is $50 \mathrm{~mm}$ ) to grouting in the right tunnel from $\mathrm{K} 27+541$ to $\mathrm{K} 27+500$ to make the stability of the surrounding rock stronger, so the tunnel can be safer.

(4) In the follow-up construction process, we must strengthen the monitoring and measurement work, and timely adjust reinforcement measures to ensure safety of lining and rib beam of Nanshan tunnel and stability of the surrounding rock [7].

After discovered the surface cracks, stopped the excavation of the left tunnel, and used the control measures aforementioned to deal with. According to the monitoring data of vault's ground settlement, to late May 2014, secondary lining of the right tunnel has been completed, so the ground settlement has been effectively controlled, and the settlement rate is significantly reduced. In August 2014, the average speed of the surface settlement in Nanshan tunnel in the range of 0 to $0.1 \mathrm{~mm} / \mathrm{d}$, and the average speed of the vault in the range of 0 to $0.2 \mathrm{~mm} / \mathrm{d}$. Ground settlement tends to be stable.

\section{Summary}

The double-arch permeable rib tunnel which has a new type of structure has high popularization and application value. Based on the practice of the construction monitoring scheme of Nanshan tunnel, and the feedback analysis of the surface cracks, the construction monitoring and feedback control of the tunnel are realized. The information feedback control technology, which is formed by the tunnel, has guided the construction and ensured the engineering quality and safety.

\section{References}

[1] Yao Zhenkai, Huang Yunping, Peng Limin. Engineering technology of highway connecting arch tunnel [M] . Beijing: People's Communications Press, 2006.

[2] Yu Fei, Chen Shanxiong, Chen Xiuhe. Analysis of transparent rib beam tunnel structure [J] . Journal of rock mechanics and Engineering, 2009, (10): 2039-2047.

[3] Industry standard of the people's Republic of China. JTG D70-2004 Code for highway tunnel design [S]. Beijing: People's Communications Press, 2004.

[4] Wang Min. Application of information feedback technology in underground engineering construction settlement control $[\mathrm{J}]$. Journal of Ocean University of China (NATURAL SCIENCE EDITION), 2014, 44(12): 97-99+110.

[5] Industry standard of the people's Republic of China. JTG F60-2009 Technical specification for highway tunnel construction [S]. Beijing: People's Communications Press, 2009.

[6] Chen Liang. Feedback analysis on construction monitoring of underground powerhouse of hydropower station. Ms D Thesis [D]. Tsinghua University, 2009.

[7] Zhao Yong. Research on deformation mechanism and control technology of soft surrounding rock in tunnel . Ph D Thesis[D]. Beijing: Beijing Jiaotong University, 2012. 